\title{
TINGKAT PENGETAHUAN IBU NIFAS TENTANG FISIOLOGI LAKTASI BERDASARKAN KARAKTERISTIK IBU DI RUANG NIFAS RUMAH SAKIT UMUM BANGLI TAHUN 2021
}

\author{
The Level of Knowledge of Public Mothers about Lactation Physiology Based on The \\ Characteristics of The Mother in The Public Room \\ Bangli General Hospital in 2021
}

\author{
Gusti Ayu Made Murtiniasih', I Komang Lindayani ${ }^{2}$, Made Widhi Gunapria Darmapatni ${ }^{3}$ \\ ${ }^{1}$ Jurusan Kebidanan, Poltekkes Kemenkes Denpasar, Denpasar, Indonesia \\ ${ }^{2}$ Jurusan Kebidanan, Poltekkes Kemenkes Denpasar, Denpasar, Indonesia \\ ${ }^{3}$ Jurusan Kebidanan, Poltekkes Kemenkes Denpasar, Denpasar, Indonesia \\ Korespondensi: Gusti Ayu Made Murtiniasih dan 082gustiayumademurtiniasih@gmail.com
}

\begin{abstract}
ABSTRAK
Latar Belakang: Fisiologi laktasi merupakan suatu proses yang meliputi produksi, dan pengeluaran air susu ibu, proses ini membutuhkan kesiapan ibu baik secara fisik dan psikologis, bayi yang telah cukup kuat untuk menyusu, serta produksi ASI yang telah sesuai untuk kebutuhan bayi yaitu 500 sampai dengan $800 \mathrm{ml}$ setiap harinya. Tujuan Penelitian Tujuan penelitian ini mengidentifikasi tingkat pengetahuan ibu nifas tentang fisiologi laktasi berdasarkan umur, pendidikan, pekerjaan, dan paritas. Metedologi: Jenis penelitian deskriptif, di RSU Bangli, data dikumpulkan dengan menggunakan kuesioner, besar sampel 50. Hasil: Hasil penelitian pengetahuan ibu nifas masih kurang 80\%, umur 20-35 tahun pengetahuannya kurang $(81,2 \%)$, pendidikan menengah pengetahuan kurang $(80,5 \%)$, pekerjaan wiraswasta pengetahuan kurang $(79,2 \%)$, multipara pengetahuan yang kurang (71,9\%). Kesimpulan: Kesimpulan berdasarkan umur, pekerjaan, pendidikan, paritas pengetahuan tingkat pengetahuan responden masih kurang tentang fisiologi laktasi.
\end{abstract}

Kata Kunci: Pengetahuan; Nifas; Fisiologi Laktasi.

\begin{abstract}
Background: The physiology of lactation is a process that includes the production and excretion of breast milk, this process requires the readiness of the mother both physically and psychologically, babies who are strong enough to breastfeed, and milk production that is suitable for the baby's needs, namely 500 to $800 \mathrm{ml}$ per day. Objectives: The purpose of this study was to identify the level of knowledge of postpartum mothers about the physiology of lactation based on age, education, occupation, and parity. Methodology: This type of descriptive research, in Bangli General Hospital, the data were collected using a questionnaire, the sample size was 50. Result: the results of the research were $80 \%$ less knowledge of postpartum mothers, 20-35 years of age had insufficient knowledge (81.2\%), secondary education had less knowledge (80.5\%), self-employed knowledge is less (79.2\%), multiparous knowledge is less (71.9\%). Conclusions: Conclusions based on age, occupation, education, knowledge parity, the level of knowledge of respondents is still lacking about the physiology of lactation.
\end{abstract}

Keywords: Knowledge; Postpartum; Lactation Physiology. 
PENDAHULUAN

\begin{tabular}{lcr}
\multicolumn{2}{c}{ Menyusui $\begin{array}{c}\text { (laktasi) } \\
\text { kelengkapan }\end{array}$ fisiologis } & dan \\
penyempurna dari sebuah & siklus \\
reproduksi & (Rejeki, 2019). & Masa \\
Reproduksi & merupakan masa dimana \\
perempuan & menjalankan & tugas \\
kehidupannya & yaitu mulai hamil,
\end{tabular} melahirkan, masa nifas dan menyusui dan masa antara yaitu merencanakan jumlah atau jarak anak dengan menggunakan alat kontrasepsi (Prijatni, 2016). Seorang wanita akan sempurna bila dalam siklus hidupnya mengalami ovulasi, menstruasi, kehamilan, melahirkan dan disempurnakan dengan menyusui (laktasi). Selama masa kehamilan, payudara ibu berkembang dan disiapkan untuk mengambil alih peran nutrisi bayi dari plasenta.

Manajemen laktasi merupakan segala daya upaya yang dilakukan untuk membantu ibu mencapai keberhasilan dalam menyusui bayinya (Sutanto, 2018). Usaha ini dilakukan ibu khususnya pada periode menyusui eksklusif yaitu 0-6 bulan pertama pasca persalinan. Keberhasilan manajemen laktasi didukung dengan pemahaman tentang fisiologi laktasi, tentang produksi dan pengeluaran ASI. Upaya ini dilakukan dalam tiga tahap, yaitu pada masa kehamilan (antenatal), sewaktu ibu dalam persalinan sampai keluar rumah sakit (perinatal) dan masa menyusui selanjutnya sampai anak berumur 2 tahun (postnatal) (Maryunani, 2015).

Proses laktasi mempunyai dua komponen penting yaitu proses produksi ASI dan proses pengeluaran ASI. Proses produksi ASI dimulai dengan pembentukkan payudara sejak embrio 18 sampai dengan 19 minggu yang dipengaruhi oleh hormon pertumbuhan. Selama masa kehamilan akan terjadi peningkatan hormon prolaktin yang berfungsi dalam produksi ASI. Walaupun hormon prolaktin meningkat selama kehamilan, ASI belum bisa keluar karena kadar hormon estrogen dan progesteron menghambat efek stimulatorik prolaktin pada sekresi susu.

Penelitian dilakukan di Rumah Sakit Umum Bangli karena Rumah Sakit Umum Bangli merupakan pusat rujukan kasus obstetri dan ginekologi untuk daerah Bangli. Persalinan yang tidak bisa ditangani di praktek mandiri bidan maupun klinik swasta akan dirujuk ke Rumah Sakit Umum Bangli untuk penanganan lanjutan. Hal ini memungkinkan bahwa pasien yang melahirkan di Rumah Sakit Umum Bangli berasal dari seluruh kecamatan di Kabupaten Bangli. Sehingga data penelitian yang akan didapatkan diharapkan bisa mewakili seluruh daerah Kabupaten Bangli.

\section{TUJUAN PENELITIAN}

Mengidentifikasi

tingkat pengetahuan ibu nifas tentang fisiologi laktasi di Ruang Nifas Rumah Sakit Umum Bangli Tahun 2021.

\section{METODE PENELITIAN}

Penelitian ini menggunakan jenis penelitian deskriptif.. Teknik sampel yang digunakan adalah Non Probability Sampling, diambil secara purposive sampling. Penelitian dilakukan pada bulan Maret sampai dengan bulan April tahun 2021 dengan menggunakan data primer. Alat pengumpulan data menggunakan kuesioner. Adapun kriteria inklusi dalam penelitian ini adalah bersedia menjadi responden, tidak memiliki kontraindikasi medis pada ibu dan bayi untuk menyusui dan ibu nifas dengan pasca persalinan normal maupun sectio secarea. Analisa data adalah univariat dilakukan secara deskriptif. Penelitian 
mendapat persetujuan komisi etik RSU Bangli.

\section{HASIL PENELITIAN}

Berdasarkan hasil penelitian ini kepada 50 orang responden pada ibu nifas tingkat pengetahuan ibu nifas tentang fisiologi laktasi seperti ditampilkan pada tabel dibawah ini:

\section{Tabel 1.}

Persentase Pengetahuan Responden Tentang Fisiologi Laktasi di Rumah Sakit Umum Bangli $(\mathrm{n}=50)$

\begin{tabular}{cccc}
\hline 1 & Baik & 2 & 4 \\
2 & Cukup & 8 & 16 \\
3 & Kurang & 40 & 80 \\
\hline & Total & 50 & 100 \\
\hline
\end{tabular}

Berdasarkan tabel 1 terlihat bahwa sebagian besar responden memiliki pengetahuan yang kurang tentang fisiologi laktasi yaitu sebanyak 40 orang $(80 \%)$, responden yang pengetahuannya cukup sebanyak delapan orang $(16 \%)$ dan responden yang pengetahuannya baik hanya dua orang $(4 \%)$.

\begin{tabular}{cccc}
\hline No. & $\begin{array}{c}\text { Tingkat } \\
\text { Pengetahuan }\end{array}$ & f & $\%$ \\
\hline
\end{tabular}

Tabel. 2

Pengetahuan Ibu Nifas Tentang Fisiologi Laktasi Berdasarkan Karakteristik di Rumah Sakit Umum Bangli $(\mathrm{n}=50)$

\begin{tabular}{|c|c|c|c|c|c|c|c|c|}
\hline \multirow{3}{*}{ Variabel } & \multicolumn{8}{|c|}{ Pengetahuan } \\
\hline & \multicolumn{2}{|c|}{ Baik } & \multicolumn{2}{|c|}{ Cukup } & \multicolumn{2}{|c|}{ Kurang } & \multicolumn{2}{|c|}{ Total } \\
\hline & $\mathbf{n}$ & $\%$ & n & $\%$ & $\mathbf{n}$ & $\%$ & $\mathrm{n}$ & $\%$ \\
\hline \multicolumn{9}{|l|}{ Umur } \\
\hline $20-35$ th & 2 & 4,2 & 7 & 14,6 & 39 & 81,2 & 48 & 100 \\
\hline$>35$ th & 0 & 0 & 1 & 50 & 1 & 50 & 2 & 100 \\
\hline \multicolumn{9}{|l|}{ Pendidikan } \\
\hline Dasar (SD) & 0 & 0 & 0 & 0 & 4 & 100 & 4 & 100 \\
\hline Menengah (SMP-SMA) & 1 & 2,4 & 7 & 17,1 & 33 & 80,5 & 41 & 100 \\
\hline Tinggi & 1 & 20 & 1 & 20 & 3 & 60 & 5 & 100 \\
\hline \multicolumn{9}{|l|}{ (Diploma-Sarjana) } \\
\hline \multicolumn{9}{|l|}{ Pekerjaan } \\
\hline IRT & 1 & 5,3 & 2 & 10,5 & 16 & 84,2 & 19 & 100 \\
\hline PNS/ & 1 & 14 & 1 & 14,3 & 5 & 71,4 & 7 & 100 \\
\hline Pegawai swasta & & 3 & & & & & & \\
\hline Wiraswasta & 0 & 0 & 5 & 20,8 & 19 & 79,2 & 24 & 100 \\
\hline \multicolumn{9}{|l|}{ Paritas } \\
\hline Primipara & 0 & 0 & 1 & 5,9 & 16 & 94,1 & 17 & 100 \\
\hline Multipara & 2 & 6,3 & 7 & 21,9 & 23 & 71,9 & 32 & 100 \\
\hline Grande multipara & 0 & 0 & 0 & 0 & 1 & 100 & 1 & 100 \\
\hline
\end{tabular}

\section{PEMBAHASAN}

Pengetahuan merupakan faktor penting dalam membentuk tindakan seseorang (overt behavior) yang berasal dari hasil tahu dan terjadi setelah orang melakukan penginderaan (Notoadmodjo, 2014). Pengetahuan diperoleh dari pengalaman sendiri atau orang lain. Pengetahuan ibu yang memadai mengenai fisiologi laktasi diantaranya pengetahuan tentang laktogenesis, pengetahuan tentang hormon laktasi, pengetahuan tentang refleks laktasi dan faktor-faktor 
yang mempengaruhi produksi dan pengeluaran ASI akan mempengaruhi dan memotivasi ibu untuk memberikan ASI eksklusif.

Masih rendahnya pengetahuan responden tentang fisiologi perlu ditingkatkan dengan melakukan upaya promosi kesehatan, sehinga target pemberian ASI Eksklusif dapat terpenuhi agar anak Indonesia terpenuhi kecukupan gizinya, tumbuh dan berkembang secara optimal.

Berdasarkan dari hasil penelitian terlihat bahwa sebagian besar ibu nifas di RSUD Bangli memiliki pengetahuan yang kurang tentang fisiologi laktasi $80 \%$, Penelitian ini sejalan dengan penelitian Andayani (2019) yang menemukan bahwa sebagian besar $(50,8 \%)$ pengetahuan responden kurang manajemen laktasi di wilayah Kerja Puskesmas Atari Jaya.

Berdasarkan pemaparan hasil penelitian sebagian besar responden $96 \%$ berada dalam rentang umur 20 tahun sampai 35 tahun berjumlah 48 orang sebagian besar pengetahuannya kurang yaitu 39 orang $(81,2 \%)$ dan tidak ada responden kelompok umur $>35$ tahun yang memiliki pengetahuan baik. Penelitian ini sejalan dengan penelitian Utami (2020) yang menemukan responden usia produktif memiliki pengetahuan rendah $(63,1 \%)$ lebih banyak dari responden yang memiliki pengetahuan tinggi $(36,9 \%)$ tentang manajemen laktasi di Wilayah Kerja Puskesmas Banyudono 1 Kabupaten Boyolali, kesimpulan penelitian tersebut umur ibu tidak ada hubungan dengan pengetahuan manajemen laktasi.

Penelitian ini berbeda dengan penelitian yang dilakukan oleh Novitasari dan Mawarti (2015) yang menemukan sebagian besar responden ibu post partum di RS PKU Muhammadiyah Yogyakarta berada dalam kategori umur yang beresiko yaitu $<20$ tahun dan $>35$ tahun. Penelitian ini menemukan bahwa responden dengan pengetahuan yang baik tentang fisiologi laktasi berada pada rentang umur yang beresiko. Rentang usia 20 tahun sampai 35 tahun merupakan usia reproduksi sehat seorang perempuan, usia $<20$ tahun usia reproduksi muda, sedangkan usia $>35$ tahun tergolong usia reproduksi tua yang berisiko tinggi pada kehamilan dan persalinan (Kementerian Pemberdayaan Perempuan dan Perlindungan Anak Republik Indonesia, 2016), begitu juga dengan fisiologi laktasi pada perempuan yang umurnya kurang dari 20 tahun, dimana organ-organ laktasi belum berfungsi dengan baik sedangkan pada umur lebih dari 35 tahun organ laktasi sudah mengalami penurunan.

Berdasarkan hasil penelitian sebagian besar responden berpendidikan menengah $(82 \%)$, pendidikan tinggi $10 \%$, dan pendidikan dasar (SD) $8 \%$. Responden pendidikan dasar (SD) seluruhnya memiliki pengetahuan kurang (100\%). Kelompok pendidikan menengah sebagian besar pengetahuan kurang 80,5\%, pengetahuan cukup $17,1 \%$ dan pengetahuan baik 2,4\%. Kelompok responden yang pendidikan tinggi pengetahuan kurang $60 \%$, pengetahuan cukup $20 \%$, dan pengetahuan baik $20 \%$. Pendidikan dapat mempengaruhi seseorang termasuk juga perilaku seseorang akan pola hidup terutama dalam memotivasi untuk berperan serta dalam pembangunan, pada umumnya makin tinggi pendidikan seseorang makin mudah menerima informasi. Semakin tinggi tingkat pendidikan seseorang, maka semakin mudah menemukan informasi, jadi semakin banyak pula pengetahuan yang dapat dimiliki oleh orang tersebut (Budiman dan Riyanto, 2016) dalam (Kalpikasari, 2019), namun berbeda dengan hasil penelitian 
ini sebagian besar pendidikan menengah dan sebagian besar pengetahuannya masih kurang tentang fisiologi laktasi. Responden yang berpendidikan tinggi masih ada yang memiliki pengetahuan yang kurang tentang fisiologi laktasi. Pada saat wawancara singkat dengan responden mengatakan jarang mengikuti kegiatan-kegiatan pelayanan kesehatan secara informal seperti misalnya penyuluhan- penyuluhan, kelas ibu hamil maupun bersumber dari leaflet atau brosur terkait fisiologi laktasi.

Hasil penelitian ini walaupun sebagai besar responden pengetahuannya kurang namun ada perbedaan persentase tingkat pengetahuan yang kurang, PNS/pegawai swasta yang tingkat pengetahuannya kurang $71,4 \%$, ibu nifas yang bekerja sebagai wiraswasta tingkat pengetahuan kurang 79,2\%, ibu rumah tangga pengetahuan yang kurang $84,2 \%$.

Hasil penelitian ini sejalan dengan penelitian Wahyuni (2014) yaitu persentase pengetahuan kurang pada ibu rumah tangga $(6,9 \%)$ lebih tinggi dari ibu yang bekerja (4,3\%). Kesimpulan dari penelitian Wahyuni (2014) ada perbedaan pengetahuan manajemen laktasi antara ibu yang bekerja dengan ibu rumah tangga di Puskemas Moyudan Slean Yogyakarta tahun 2014.

Perbedaan pengetahuan dari ibu yang bekerja dengan ibu rumah tangga disebabkan perbedaan dalam memperoleh informasi tentang fisiologi laktasi. Informasi yang didapat ibu yang bekerja tentang manajemen laktasi diperoleh dari media elektronik, berupa TV dan sebagian kecil bersumber dari media cetak dari leaflet, dan ada ibu rumah tangga belum pernah mendengar informasi tentang manajemen laktasi (Wahyuni, 2014).

Hasil penelitian ini pada ibu multipara yaitu pengetahuan baik $6,3 \%$, pengetahuan cukup $21,9 \%$. Pengetahuan ibu multipara lebih banyak daripada pengetahuan ibu primipara karena faktor pengalaman dalam hal menyusui. Dengan pengalaman maka seseorang dapat mempunyai pengetahuan yang lebih baik daripada yang belum rnemperoleh pengalaman (Khoiriyah dan Prihatini, 2011). Namun satu orang grandemultipara pada penelitian ini pengetahuannya kurang. Dilihat dari tingkat pendidikan, satu orang yang grandemulitpara tersebut berpendidikan SMP. Pendidikan yang rendah mengakibatkan seseorang kurang mengerti tentang manfaat fisiologi laktasi.

\section{KESIMPULAN}

Sebagian besar responden dengan kategori pengetahuan kurang sebesar $80 \%$. Sebagian besar responden berada pada kelompok umur 20-35tahun yaitu dengan kategori pengetahuan kurang sebesar $81,2 \%$. Sebagian besar responden berada pada kelompok pendidikan menengah (SMP-SMA) dengan kategori pengetahuan kurang sebesar 80,5\%. Sebagian besar responden bekerja sebagai wiraswasta dengan kategori pengetahuan kurang sebesar 79,2\%. Sebagian besar responden adalah multipara dengan kategori pengetahuan kurang 94,1\%.

\section{DAFTAR PUSTAKA}

Andayani R. (2019). Hubungan pengetahuan ibu tentan manajemen laktasi dengan pemberian asi eksklusif di wilayah kerja puskesmas atari jaya kecamtan lalembuu kabupaten konawe selatan. Naskah Publikasi. Kendari: Politeknik Kesehatan Kendari.

Budiman dan Riyanto. A. (2016). Kapita selekta kuesioner pengetahuan dan sikap dalam 
penelitian kesehatan. Salemda Medika. Jakarta. p. pp 66-69.

Kementrian Pemberdayaan Perempuan dan Perlindungan Anak Republik Indonesia. (2016). Wanita perlu Pahami Kesehatan Reproduksi. Bengkulu: Kementrian Pemberdayaan Perempuan dan Perlindungan Anak R.I.

Maryunani, A. (2015). Inisiasi menyusui dini, asi eksklusif dan manajemen laktasi. DKI Jakarta: CV Trans Info Media.

Notoatmodjo, S. (2014). Ilmu perilaku kesehatan. Jakarta: PT. Rineka Cipta.

Novitasari dan Mawarti. (2015). Hubungan umur ibu dengan onset laktasi pada ibu post partum di rumah sakit PKU muhammadiyah yogyakarta. Naskah Publikasi. Yogakarta. Sekolah Tinggi 'Aisyiyah Yogyakarta.

Prijatni, I., dan Rahayu, I. (2016). Bahan ajar kebidanan: kesehatan reproduksi dan keluarga berencana. Jakarta : Kemenkes RI Pusat Pendidikan Sumber Daya Manusia, Badan Pengembangan Dan Pemberdayaan Sumber Daya Manusia Kesehatan.

Rejeki, S.P. (2019). Catatan kami tentang ASI. Yogyakarta : Oksana.

Utami, R.I., (2020). Hubungan antara usia, pendidikan dan pekerjaan dengan pengetahuan manajemen laktaso pada ibu yang memiliki anak usia -23 bulan di Wilayah Kerja Puskesmas Banyudono No 1 Kabupaten Boyolali tahun 2019. Skripsi. Surakarta. Universitas Muhammadiyah Surakarta.
Wahyuni. 2014. Perbedaan Pengetahuan Manajemen Laktasi Antara Ibu Bekerja dan Tidak Bekerja di Puskesmas Moyu dan Sleman Yogyakarta Tahun 2014. Yogyakarta. Widyastuti,N. R.,2020. Gambaran Pengetahuan, Sikap Dan Tindakan Ibu Dlam Manajemen Laktasi Pada Bayi Usia 0-6 Bulan Di Wilayah Kerja Puskesmas Abepantai Jayapura. Jayapura : Healthy Papua Mei 2020, Vol. 3 No. 1: 109-113. 